\title{
Duas transcrições das Siete Canciones Populares Españolas de Manuel de Falla: um estudo comparativo
}

\author{
Ângela Maria Ferrari (Universidade Federal de Santa Maria, Santa Maria, Rio Grande do Sul, Brasil) \\ angferrari2003@yahoo.com.br
}

Felipe Avellar de Aquino (Universidade Federal da Paraíba, João Pessoa, Paraíba, Brasil) f.avellardeaquino@gmail.com

\begin{abstract}
Resumo: Este artigo busca refletir sobre o processo de reelaboração musical a partir de um estudo comparativo entre as versões de Maurice Maréchal e Emilio Colón, violoncelistas de diferentes gerações, que realizaram transcrições das Siete Canciones Populares Españolas de Manuel de Falla, para violoncelo e piano. O trabalho surgiu como consequência do estudo biográfico do violoncelista e pedagogo francês, Maurice Maréchal, que, mesmo estando presente na vida dos violoncelistas atuais, principalmente por meio de suas transcrições, é relativamente pouco lembrado. É também intenção deste trabalho analisar as decisões que permeiam as transcrições da obra em questão, abordando aspectos técnicos específicos do instrumento, como também seu resultado sonoro.

Palavras-chaves: Transcrição; Arranjo; Repertório do violoncelo; Manuel de Falla.
\end{abstract}

Two transcriptions of Manuel de Falla’s Siete Canciones Populares Españolas: a comparative study

Abstract: This article aims to discuss the process of music transcription through a comparative study of two different versions of the same work. Maurice Maréchal and Emilio Colón, cellists from different generations, both worked on arrangements of Falla's Siete Canciones Populares Españolas. The motivation for this paper came from the studying of the life of Maréchal, a French cellist and pedagogue, who was responsible for many transcriptions that enlarged the cello literature, but seems to be somewhat forgotten by the new generation of instrumentalists. Thus, this work intends to analyze the musical decisions made by both cellists in their transcriptions, discussing technical issues as well as the sounding results.

Keywords: Transcription; Arrangement; Cello repertoire; Manuel de Falla.

\section{Introdução}

A transcrição musical tem sido uma prática que permeia a História da Música ocidental desde o florescimento da música instrumental no período Renascentista. Considerada uma reelaboração musical, ainda hoje é bastante explorada por compositores e instrumentistas que empregam este recurso para, em muitos casos, ampliar o repertório de seu instrumento ou, até mesmo, com fins de utilização pedagógica deste material. Além disso, é notório que esta prática espelha as decisões técnicas e musicais tomadas por aqueles que transcrevem a obra. Sendo assim, é intuito deste trabalho refletir sobre o processo de reelaboração musical a partir de um estudo comparativo entre duas transcrições realizadas por violoncelistas de gerações distintas, permitindo, de certa forma, observar o desenvolvimento da própria técnica do violoncelo entre os séculos XX e XXI.

Chama-se a atenção para o fato de que a motivação deste trabalho é consequência de um estudo sobre a vida de Maurice Maréchal (1892-1964), eminente violoncelista e pedagogo francês que, mesmo estando presente na vida dos violoncelistas atuais, por meio de suas transcrições, é pouco conhecido pelas novas gerações. No presente trabalho, procuramos destacar sua concepção como arranjador, comparando a transcrição da suíte de Manuel de Falla, realizada em 1925, com a versão elaborada pelo violoncelista Emilio Colón ${ }^{1}$, publicada em 2002. Desta forma, enfatizamos as decisões editoriais de cada violoncelista, ao mesmo tempo em que é possível demonstrar a evolução técnica e estética da performance do instrumento ocorridas no espaço de 77 anos que separam as duas versões. Ademais, enquanto conservam um olhar preciso sobre a obra original, apresentam, em seu escopo, escolhas que denotam as respectivas marcas dos artistas que as transcreveram. 


\section{Maurice Maréchal: breves considerações sobre sua vida e obra}

Maurice Maréchal foi um dos expoentes da escola francesa do violoncelo no início do século XX. Nascido em Dijon, em 03 de outubro de 1892, faleceu em Paris, em 19 de abril de 1964. Filho de um funcionário dos Correios, Jules Jacques Maréchal, e de Marthe Justine Maréchal, a maior incentivadora de sua carreira. É importante salientar que sua atividade musical atravessou as duas grandes guerras mundiais, sendo que ele, na primeira delas, tomou efetivamente parte como soldado. Durante toda sua vida, teve o costume de escrever suas impressões cotidianas. Neste sentido, os anos de guerra foram particularmente comentados em pequenos cadernos de anotações que levava em seu bolso. Segundo Lambert (2003, p. 19, tradução nossa), "entre 3 de maio de 1914 e 8 de fevereiro de 1919, nove livros de apontamentos seguiram-se dentro de um bolso do uniforme, diminutos, e de formato minúsculo a fim de não atrapalhar os movimentos"².

Mesmo durante a guerra, Maréchal não se afastou da música nem de seu instrumento, uma vez que dois companheiros marceneiros construíram para ele um violoncelo rústico, a partir de tábuas de caixa de munição ${ }^{3}$. Esse violoncelo foi batizado de "Le Poilu" e encontra-se preservado até os dias de hoje no Musée de la Musique de Paris ${ }^{4}$.

De acordo com algumas notas sobre o violoncelista, no site do Ministère de Affaires Étrangèr (MAURICE MARÉCHAL..., 2013) da França, sabe-se que pouco restou de sua discografia e que suas partituras foram posteriormente vendidas para o violoncelista Mstislav Rostropovich. Em seu livro, Maurice Maréchal: la voix du violoncelle, Alain Lambert (2003) relaciona o repertório que Maréchal costumava tocar, além de listar os compositores com os quais conviveu, a exemplo de Claude Debussy, Maurice Ravel, André Caplet, Arthur Honegger e Darius Milhaud. Como registro desta proximidade, a partitura da Sonata para violoncelo e piano de Claude Debussy, que pertencia a Maréchal, possui dedicatória do próprio compositor (GINSBURG, 1983, p. 179) e encontra-se em um museu na Rússia. Ademais, Maréchal colaborou com Ravel ao longo do processo composicional da Sonata para violino e violoncelo, tendo realizado a primeira audição desta obra, ao lado de Hélène Jourdan-Morhange, na Sala Playel de Paris, em 1922 (GINSBURG, 1983, p. 181-182).

Segundo Ginsburg (1983), Maréchal realizou transcrições de obras de diversos períodos e estilos musicais, abrangendo um repertório que se estende de Rameau a Ravel. Não obstante, o autor destaca a fidelidade de Maréchal ao caráter de cada composição, como também à sua interpretação artística (GINSBURG, 1983, p. 179-181). De fato, seu fascínio pelo elemento estritamente musical, além do interesse em ampliar o repertório do instrumento, motivou o violoncelista a trabalhar com transcrições. Da mesma forma, Maurice Maréchal também atuou como editor de obras que se incorporaram ao repertório padrão do instrumento, a exemplo do Concerto para viola e cordas em Dó menor, cuja autoria é atribuída a Johann Christian Bach, e que teve sua versão para violoncelo editada por Maréchal a partir da reconstituição e harmonização realizadas por Henri e Francis Casadesus.

\section{A arte da transcrição}

A transcrição ou reelaboração musical tem sido, ao longo da história da música, uma prática efetivamente recorrente, seja com vistas a ampliar o repertório de um determinado instrumento ou a fim de se oferecer novos desafios técnicos e virtuosísticos ao intérprete. Segundo Pereira:

A prática de se reelaborar obras de um meio instrumental para outro diferente já era comum no período da renascença, onde a música instrumental com frequência consistia em transcrições da música vocal. Até o final do século XVIII observa-se que a relação com a prática de reelaborar através de arranjos, transcrições, etc., acontecia naturalmente como um tipo de especificidade da música. (PEREIRA, 2011, p. 3). 
Como visto, a transcrição ou reelaboração musical não é uma prática nova, seus exemplos se desdobram ao longo de toda a literatura instrumental. A título de ilustração, tomando-se por base a literatura violoncelística, podemos citar a transcrição da Suíte $N^{o} 5$ em Dó menor, BWV 1011 para violoncelo solo de J.S. Bach, posteriormente transcrita pelo próprio autor, para alaúde solo, e transposta para a tonalidade de sol menor. Da mesma forma, a Sonata em Lá Maior de César Frank, originalmente para violino e piano, vem a ser uma das transcrições mais representativas incorporadas ao repertório do violoncelo. Esta versão foi realizada pelo violoncelista Jules Delsart, com a aprovação do próprio compositor, e acabou por se tornar uma das sonatas mais importantes da literatura do instrumento. De forma mais abrangente, podemos citar Franz Liszt, no séc. XIX, que se notabilizou por realizar relevantes transcrições para piano, que incluem sua versão das sinfonias de Beethoven, além da Sinfonia Fantástica de Berlioz.

Desta forma, é pertinente considerar a transcrição musical como o ato de reescrever uma obra composta para um determinado meio, direcionada para uma outra configuração ou formação musical. A partir da própria etimologia da palavra, Pereira (2011, p. 52) afirma que, "além de ser uma prática que possui maior grau de fidelidade com o original, traz também um procedimento no qual sempre há uma mudança do meio instrumental, ou seja, 'transporta-se' de um instrumento a outro, ou de um meio a outro”. Além do mais, segundo a mesma autora, "a transcrição não é tão livre, pois o intuito é guardar ao máximo a ideia original” (PEREIRA, 2011, p. 52). Segundo o Dicionário Harvard (RANDEL, 1986, p. 53), os termos arranjo e transcrição são empregados muitas vezes com o mesmo significado, no entanto, o vocábulo transcrição sempre está relacionado a um grau de maior fidelidade ao original. Ademais, constata-se, a partir de um olhar abrangente sobre a literatura musical, que transcrição musical é uma prática recorrente até os dias de hoje.

\section{As Siete Canciones Populares Españolas de Manuel de Falla}

Manuel de Falla (1874-1946) foi, sem dúvida, um dos maiores expoentes da música espanhola do século XX. Nasceu em Cádiz, região da Andaluzia, e foi fortemente influenciado por seu professor de composição, Felipe Pedrell (1841-1922), pioneiro do nacionalismo musical espanhol, que o guiou por este caminho ${ }^{5}$. Neste sentido, Falla desenvolveu importante papel ao compilar e arranjar canções folclóricas de seu país, incorporando os elementos da música popular, notadamente quanto aos aspectos rítmicos e melódicos, em sua própria obra (GROUT; PALISCA, 1988, p. 788).

Entre 1907 e 1914, Falla residiu em Paris, onde conviveu com compositores como Claude Debussy (1862-1918), Paul Dukas (1865-1935) e Maurice Ravel (1875-1937), consequentemente incorporando elementos do impressionismo francês em sua própria linguagem composicional. Podemos afirmar que sua obra se caracteriza por englobar elementos nacionalistas combinados com a harmonia impressionista, aliados ainda ao vigor rítmico e à uma escrita virtuosística. Este último elemento é, de certo, oriundo do virtuosismo presente na música instrumental flamenca.

As Siete Canciones Populares Españolas foram escritas em Paris, entre 1914-1915, originalmente para voz e piano, e dedicadas à patronesse das artes Ida Godebska. Neste caso, Manuel de Falla utilizou-se de canções e danças folclóricas espanholas para estruturar este conciso ciclo. No entanto, em diversos momentos, pode-se claramente perceber o emprego de sonoridades impressionistas em sua harmonia.

Salienta-se que esta peça foi transcrita para várias combinações instrumentais, sendo que, apenas para a formação violoncelo e piano, temos duas transcrições distintas, elaboradas pelos violoncelistas Maurice Maréchal e Emilio Colón, respectivamente. Na ver- 
dade, Suite Populaire Espagnole foi o título dado à versão instrumental das Siete Canciones Populares Españolas, cuja adaptação para violino e piano foi elaborada pelo violinista polonês Paul Kochański, conjuntamente com Manuel de Falla. Os dois eram muito próximos e existem registros de que se apresentavam juntos com certa frequência, fato atestado também pela dedicatória da versão intitulada Suite Populaire Espagnole ao próprio violinista.

Na realidade, além de concertista e professor, Kochański foi também compositor e arranjador, que costumava trabalhar em colaboração com outros compositores de sua época. Neste sentido, ratifica Greive:

As transcrições de Kochański representam uma conexão pessoal com o compositor original. Por exemplo, em 1907, Kochański não apenas se apresentou em Bilbao com Manuel de Falla ao piano, mas também auxiliou financeiramente a ida do compositor para Paris, consequentemente propiciando o crescimento profissional do mesmo. As transcrições das Sete canções populares espanholas para voz e piano (1914-15) as quais foram revisadas por Kochański e o compositor respectivamente foram dedicadas para o violinista. Renomeadas Suite popular espanhola essa obra está entre as mais populares transcrições de Kochański'. (GREIVE, 1998, tradução nossa).

Apesar deste estudo se tratar de um trabalho comparativo, a sequência das canções aqui abordadas segue a transcrição de Maurice Maréchal, que, por sua vez, omite a Seguidilla Murciana, conforme explicado adiante. Por conseguinte, a análise partirá do trabalho efetuado por este arranjador e obedecerá a ordem das canções de acordo com a versão para violino e piano elaborada por Falla e Kochański.

\section{Análise comparativa entre as transcrições de Maréchal e Colón 5.1. El Paño Moruno}

El Paño Moruno é o movimento de abertura nas três versões aqui abordadas, inclusive em sua versão original para canto e piano. Como afirma Park (2013, p. 7, tradução nossa), "a melodia dessa canção é extraída de uma ária popular da região da Andaluzia 'El paño', no entanto Falla altera ligeiramente a melodia"7. A versão de Manuel de Falla possui uma introdução de 23 compassos antes da entrada da voz. Por outro lado, em suas respectivas versões, tanto Maréchal quanto Colón optaram por reelaborar esses compassos, duplicando, na linha do violoncelo, o material complementar à textura que, originalmente, é realizada pela mão direita do piano. Todavia, cada arranjador utiliza esse material de maneira ligeiramente diferente, como verifica-se no Exemplo. 1.

Desta forma, Maréchal, nos quatro primeiros compassos, coloca apenas a nota lá harmônico (lá4), ao passo em que Colón explora os harmônicos naturais produzidos sobre as notas lá/ré (lá2/ré3), finalizando em sol/mi (sol2/mi3) - lá/ré (lá2/ré3), a fim de enriquecer a textura.

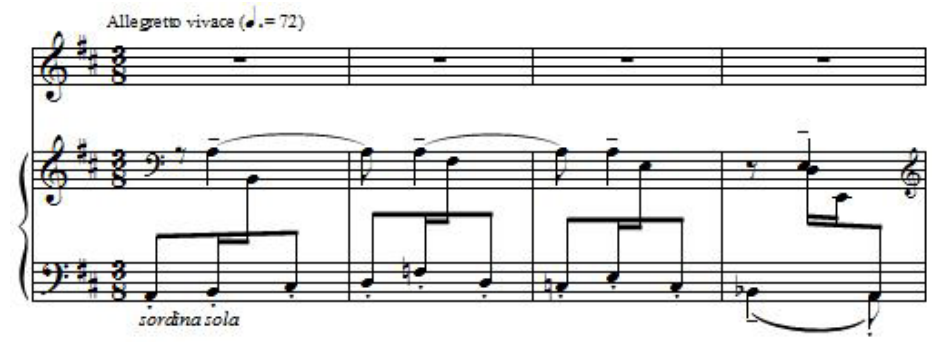

Exemplo 1 a - Siete Canciones Populares Españolas - El Paño Moruno (comp. 1-4).

Fonte: Versão original para canto e piano de Manuel de Falla (1922). 


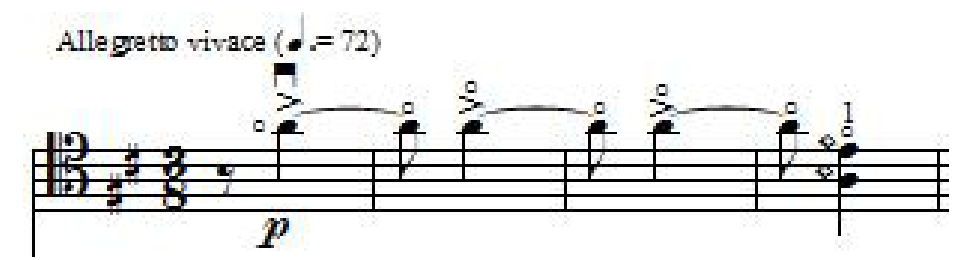

Exemplo 1b - Suite Populaire Espagnole - El Paño Moruno (comp. 1-4). Fonte: Manuel de Falla (1925) (transcrição de Maurice Maréchal).

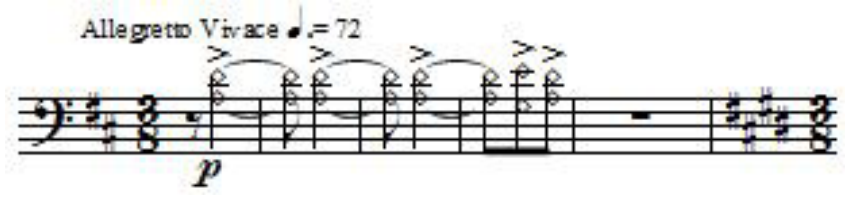

Exemplo 1c - Siete Canciones Populares Españolas - El Paño Moruno (comp. 1-4).

Fonte: Manuel de Falla (2002) (transcrição de Emilio Colón).

Segundo Park, "em termos da técnica violoncelística, harmônicos e vários pizzicatos são usados no 'El paño moruno"”, efeitos esses que enfatizam coloridos e texturas musicais; salientando que, "como os harmônicos do violoncelo dobram as mesmas notas, duas oitavas acima que o segundo tempo acentuado do piano, o acompanhamento obtém efetivamente mais energia, a partir da parte do violoncelo" (Park, 2013, p. 9, tradução nossa) ${ }^{9}$, aspecto que, ao mesmo tempo, enfatiza o contratempo.

A partir do comp. 5, apesar de ambos indicarem pizzicatos para o violoncelo, cada arranjador optou por iniciar a sequência de pizzicatos por uma nota diferente. Inclusive, no comp. 7, Colón transcreve para o violoncelo exatamente o que a mão direita do piano está realizando, ao incluir, neste caso, pizzicatos de mão esquerda. Este elemento explora, de maneira sutil, gestos de virtuosismo. Esta, no entanto, não é a opção de Maréchal, que opta por uma linha do violoncelo em pizzicatos de uma forma mais simples, como pode ser verificado no Exemplo 2.

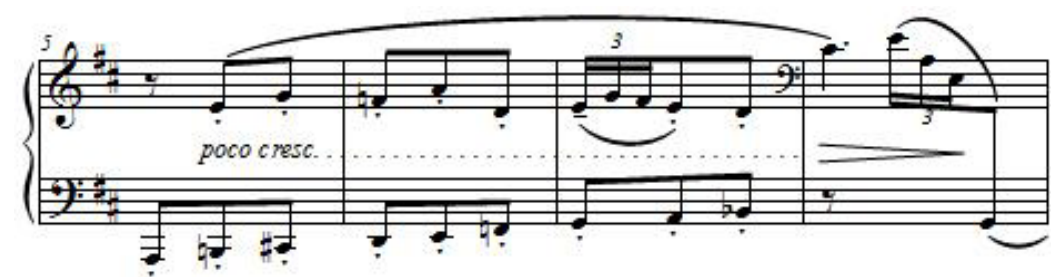

Exemplo 2a - Siete Canciones Populares Españolas - El Paño Moruno (comp. 5-8).

Fonte: Versão original para canto e piano de Manuel de Falla (1922).

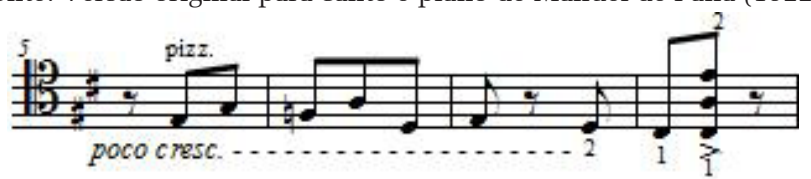

Exemplo 2b - Siete Canciones Populares Españolas - El Paño Moruno (comp. 5-8).

Fonte: Manuel de Falla (1925) (transcrição de Maurice Maréchal).

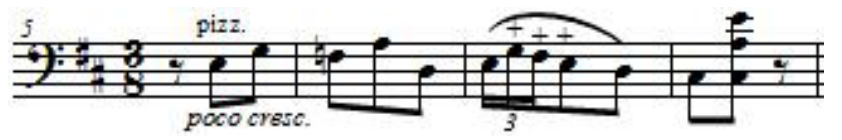

Exemplo 2c - Siete Canciones Populares Españolas - El Paño Moruno (comp. 5-8).

Fonte: Manuel de Falla (2002) (transcrição de Emilio Colón). 
Entretanto, há momentos nos quais as decisões dos dois violoncelistas se assemelham. Como é o caso dos comp. 20-22, nos quais os dois instrumentistas optaram por escrever acordes em pizzicatos para o arpejo que acontece, originalmente, na parte do piano. Observa-se que Colón apenas acrescenta a indicação quasi chitarra, em referência à textura aqui criada.

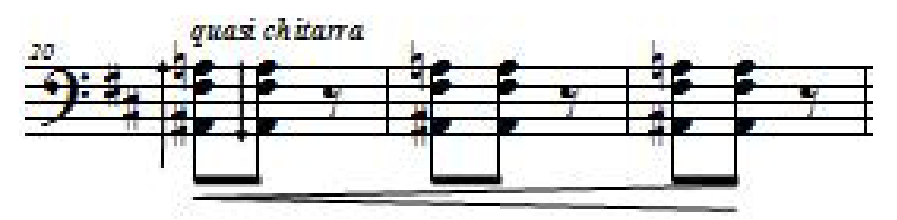

Exemplo 3 - Siete Canciones Populares Españolas - El Paño Moruno (comp. 20-22).

Fonte: Manuel de Falla (2002) (transcrição de Emilio Colón).

Todavia, os dois arranjadores transpõem a parte da voz de maneira literal para o violoncelo. Consequentemente, ao comparar as duas versões do El Paño Moruno, concluise que as transcrições de Maréchal e Colón diferem apenas em alguns breves compassos. Destaca-se, além disso, que essas diferenças são superficiais, pois não há nenhuma decisão substancial no que tange à condução melódico-harmônica, distribuição rítmica ou até mesmo quanto a elementos de dinâmica e fraseado.

\subsection{Seguidilla Murciana}

A segunda canção do ciclo, em sua versão original para canto e piano, é uma Seguidilla Murciana, dança oriunda da província autônoma de Múrcia, situada no sudeste da Espanha. Trata-se, em sua essência, de uma dança em compasso ternário com andamento rápido. Maurice Maréchal, por seguir a ordem da então Suíte Popular Espanhola, não a inclui em seu arranjo. Como resultado, o ciclo de Maréchal conta apenas com seis das sete canções e, por conseguinte, ao se espelhar no arranjo de Paul Kochański, a disposição das canções na transcrição de Maréchal também não segue a ordem original da versão vocal do compositor. Já Emilio Colón, por outro lado, as transcreve em sua íntegra, seguindo a ordem original da versão de Manuel de Falla para voz e piano, mantendo o título original.

Embora não haja nenhum relato quanto ao motivo da omissão deste movimento na versão da suíte instrumental, percebe-se que a Seguidilla Murciana tem um caráter vocal em estilo declamatório que, provavelmente, não se adequaria à linguagem violinística motivo provável para a omissão deste movimento na versão de Kochański. A retirada desta canção, por sua vez, resultou na necessidade de um completo reordenamento da sequência dos movimentos. Desta forma, uma vez que Maréchal tomou a versão de Kochański como ponto de partida para seu arranjo resultou na mesma estrutura organizacional. Por outro lado, Colón antecipou com precisão as características vocais do violoncelo, realizando uma transcrição mais próxima do original, que mantém a integralidade das canções presentes na versão original do ciclo. 
Tabela 1 - Estrutura organizacional de três versões da obra de M. de Falla

\begin{tabular}{|c|c|c|c|c|c|c|c|}
\hline \multirow{2}{*}{ Versão } & \multicolumn{7}{|c|}{ Movimento } \\
\hline & 1 & 2 & 3 & 4 & 5 & 6 & 7 \\
\hline $\begin{array}{l}\text { Original M. } \\
\text { de Falla }\end{array}$ & $\begin{array}{l}\text { El Paño } \\
\text { Moruno }\end{array}$ & $\begin{array}{l}\text { Seguidilla } \\
\text { Murciana }\end{array}$ & Asturiana & Jota & Nana & Canción & Polo \\
\hline M. Maréchal & $\begin{array}{l}\text { El Paño } \\
\text { Moruno }\end{array}$ & Nana & Canción & Polo & Asturiana & Jota & \\
\hline E. Colón & $\begin{array}{l}\text { El Paño } \\
\text { Moruno }\end{array}$ & $\begin{array}{l}\text { Seguidilla } \\
\text { Murciana }\end{array}$ & Asturiana & Jota & Nana & Canción & Polo \\
\hline
\end{tabular}

Fonte: AMF (2018).

Conjectura-se que os andamentos das canções, que resultam em características como "alegre" e "triste”, ou "rápido" e "lento", poderiam se constituir nos critérios determinados por Falla/Kochański para estipular a ordem dos movimentos da Suite Populaire Espagnole, formando assim duas sequências de andamentos rápido - lento - rápido. Em contraposição, a sequência estabelecida originalmente nas Siete Canciones Populares Españolas sugere uma estrutura que forma, na verdade, uma sequência palindrômica. Desta forma, as canções estão ordenadas em rápido - rápido - lento - rápido - lento - rápido - rápido, ou seja, a mesma sequência lida de trás para frente.

Tabela 2 - Sequência de movimentos de acordo com Maurice Maréchal.

\begin{tabular}{|l|l|l|l|l|}
\hline Canção & Caráter & $\begin{array}{l}\text { Fórmula de } \\
\text { compasso }\end{array}$ & Metrônomo & Andamento \\
\hline El Paño Moruno & Allegretto vivace & $3 / 8$ &..$=72$ & Rápido \\
\hline Nana & Calmo e sostenuno & $2 / 4$ &.$=42$ & Lento \\
\hline Canción & Allegretto & $6 / 8$ &..$=63$ & Rápido \\
\hline Polo & Vivo & $3 / 8$ &..$=80$ & Rápido \\
\hline Asturiana & Andante tranquillo & $3 / 4$ &.$=66$ & Lento \\
\hline Jota & Allegro vivo & $3 / 8$ & $. \cdot=92$ & Rápido \\
\hline
\end{tabular}

Fonte: AMF (2018). 
Tabela 3 - Sequência de movimentos nas versões de Manuel de Falla e Emilio Colón

\begin{tabular}{|l|l|l|l|l|}
\hline Canção & Caráter & $\begin{array}{l}\text { Fórmula de } \\
\text { Compasso }\end{array}$ & Metrônomo & Andamento \\
\hline El Paño Moruno & Allegro vivace & $3 / 8$ &..$=72$ & Rápido \\
\hline $\begin{array}{l}\text { Seguidilla } \\
\text { Murciana }\end{array}$ & Allegro spiritoso & $3 / 4$ &..$=60$ & Rápido \\
\hline Asturiana & $\begin{array}{l}\text { Andante } \\
\text { tranquillo }\end{array}$ & $3 / 4$ &.$=66$ & Lento \\
\hline Jota & Allegro vivo & $3 / 8$ &.$=62$ & Rápido \\
\hline Nana & Calmo e sostenuno & $2 / 4$ &..$=92$ & Lento \\
\hline Canción & Allegretto & $6 / 8$ &..$=42$ & Rápido \\
\hline Polo & Vivo & $3 / 8$ &..$=80$ & Rápido \\
\hline
\end{tabular}

Fonte: AMF (2018).

Curiosamente, o texto da primeira canção, El Paño Moruno, ao falar sobre um pano manchado, insinua questões da "virtude perdida" de uma mulher, em referência aos padrões morais da época. Neste sentido, Gislason (2014, tradução nossa) faz referência a que "El Paño Moruno (O Pano Mouro) dá um não muito velado conselho para que jovens garotas evitem a 'mancha' de um romance ilícito, enquanto a segunda, a Seguidilla Murciana, consiste em um intenso argumento com insulto insistente e amargo gracejo" ${ }^{10}$. Desta feita, verifica-se que os textos destas canções, em muitos pontos, abordam os costumes e os valores obedecidos à época.

\subsection{Nana}

A segunda canção do ciclo arranjado por Maurice Maréchal é a Nana, melodia que remonta à infância do compositor, como bem apontado por Park (2013, p. 22, tradução nossa): "A nana é uma canção de ninar andaluz, que Falla escutava de sua mãe durante a infância".11

Trata-se de uma canção bastante curta, estruturada em forma binária monotemática e que, originalmente, possuía apenas 20 compassos. Conquanto, ambos os violoncelistas a expandem por meio da adição de mais uma repetição do tema, desta feita, apresentado em uma oitava acima do original. Na versão de Maréchal, o tema é simplesmente repetido uma vez mais, expandindo-o para 29 compassos. Já Colón elabora toda uma seção A', compreendendo os compassos 20 a 37.

Park, ao comentar a transcrição expandida realizada por Maréchal (comp. 1-37), esclarece que:

Nana está em forma binária e estruturada da seguinte maneira: A (comp. 1-19) - A' (comp. 20-37). Ao contrário da versão vocal original de 'Nana' escrita por Falla, que tem apenas um verso, o arranjo para violoncelo tem uma seção repetida e executada uma oitava acima. A repetição é basicamente a mesma do primeiro verso. ${ }^{12}$ (PARK, 2013, p. 22, tradução nossa). 


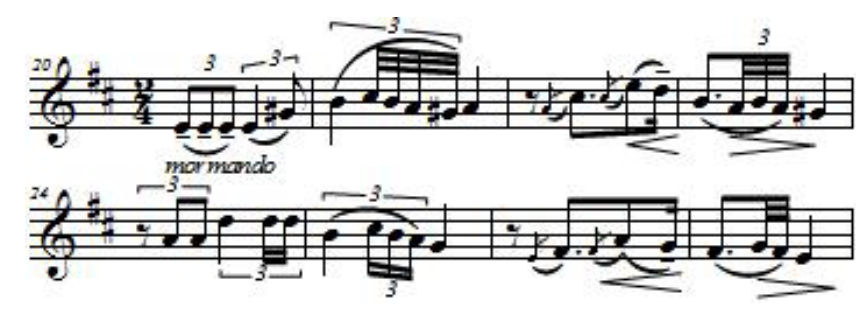

Exemplo 4 - Siete Canciones Populares Españolas - Nana (comp. 20-27).

Fonte: Manuel de Falla (2002) (transcrição de Emilio Colón).

\subsection{Canción}

O terceiro movimento da Suite Populaire Espanhole é intitulado Canción. Segundo Nevado ([entre 2001 e 2015], tradução nossa), este trata-se de "um canto de amor doce amargo (apesar da indicação de Falla para o canto: 'com grazia') oriundo de Granada, para cujo acompanhamento Falla constrói um ritmo obstinado que culminará fundindo-se com a voz ou o violoncelo em uma brevíssima coda”. ${ }^{13}$ Além do mais, Nevado ([entre 2001 e 2015], tradução nossa) comenta a versão de Maréchal, apontando que:

Na versão para violoncelo e piano, Maréchal realiza algumas variantes para exibição do solista, como escrever o tema no compasso 31 precedido de um grande crescendo em cordas duplas e dinâmica $f f$, quando a partitura original se move no âmbito do $p p$. Assim mesmo, reserva ao violoncelo uma nota ligada que ascende de uma oitava (com glissando opcional) nos três últimos compassos, inexistentes na versão da voz. ${ }^{14}$

Verifica-se que ambas as versões (Maréchal e Colón) possuem mais uma apresentação completa do tema (12 compassos, mais 2 compassos finais).

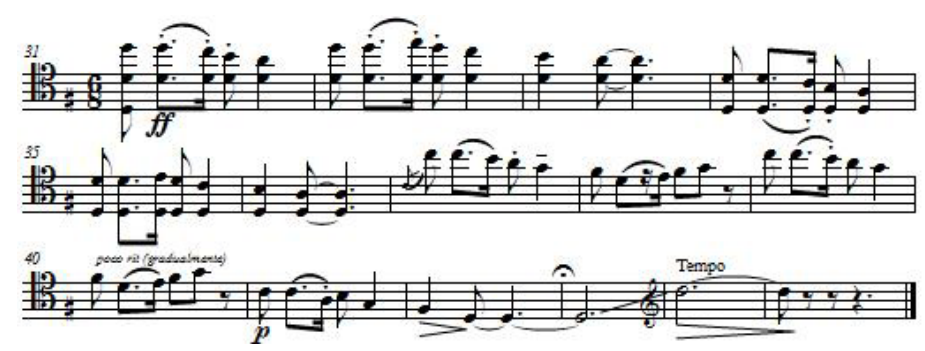

Exemplo 5a - Suite Populaire Espagnole - Canción (comp. 31-45).

Fonte: Manuel de Falla (1925) (transcrição de Maurice Maréchal).

Colón ainda apresenta uma variante deste material, ao colocar, na segunda repetição do tema, seis compassos em harmônicos, cuja intensão é de se explorar sonoridades e colorações distintas do violoncelo e, ao mesmo tempo, enriquecer a textura.

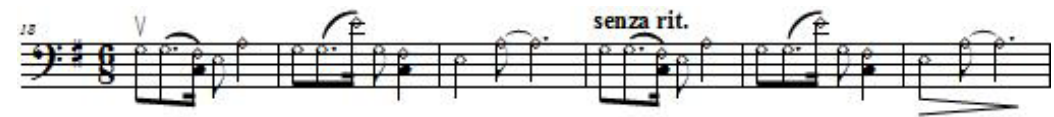

Exemplo 5b - Siete Canciones Populares Españolas - Canción (comp. 18-23).

Fonte: Manuel de Falla (2002) (transcrição de Emilio Colón).

\subsection{Polo}

Maurice Maréchal, seguindo a adaptação de Kochański, opta por colocar o Polo como o quarto movimento em seu ciclo. Todavia, Nevado ([entre 2001 e 2015], tradução nossa), ao comparar com a versão vocal, atesta que esta canção "é a mais brilhante e pungente do ciclo, motivo pelo qual Falla optou por deixá-la para o final. O autor olha novamente para a 
Andaluzia e ao Canto Jondo". ${ }^{15}$

O Polo é uma canção viva e, segundo Lorca (1922, tradução nossa), em palestra proferida na cidade de Granada, intitulada Importancia histórica y artística del primitivo canto Andaluz llamado 'Cante Jondo', afirma que “o nome cante jondo é dado a uma categoria de canção Andaluza, cujo perfeito e genuíno protótipo é a Cigana Siguiriya, e da qual derivam outras canções preservadas pelo povo, como os polos, martinetes, carceleras e soleares". ${ }^{16}$

Sobre as Siguiriyas citadas por Lorca (1922) como o protótipo dos cante jondo, Zussman (1995, p. 33, tradução nossa) afirma que “a Siguiriya (Siguiriyas, plural) foi primeiramente chamada de Seguida. Mais tarde o sufixo diminutivo -illa foi acrescentado, formando a Seguidilla. Por meio de uma deformação fonética, a Seguidilla ficou conhecida como Siguiriyas". ${ }^{17}$ Como se pode constatar, tanto o Polo como a Seguidilla são canções com origens na Andaluzia, região de nascimento de Falla.

Lorca (1922), em seu texto, enaltece a pesquisa dos elementos folclóricos realizada por Falla, notadamente sobre o canto jondo, salientando que este é o único canto do continente europeu que ainda preserva a pureza e as qualidades primitivas dos povos orientais, dando a impressão de uma prosa cantada cujo texto perde a noção de ritmo métrico. Em tempo, Lorca (1922) assevera as amplas inflexões vocais, enriquecidas por floreios ornamentais, com presença do elemento cigano. Para Lorca (1922, tradução nossa), "o cante jondo se aproxima dos pássaros, do canto do galo e da música natural do bosque e da fonte". ${ }^{18}$

Neste caso, as transcrições de Maréchal e de Colón são exatamente idênticas e têm como intenção reproduzir, o mais fielmente possível, a linha melódica construída sobre notas repetidas em andamento muito rápido. De acordo com Park (2013, p. 31, tradução nossa), "as expressões musicais formadas por notas rápidas repetidas de maneira áspera, com acentos e staccatos, expressam o sofrimento e o sentimento amargo do narrador" ${ }^{19}$, muito provavelmente oriundos do cante jondo, conforme abordado anteriormente.

\subsection{Asturiana}

A Asturiana é a penúltima canção no ciclo arranjado por Maréchal. Trata-se, originalmente, de uma canção lenta e triste. Park (2013, p. 15, tradução nossa) afirma que "a canção de lamento Asturiana vem das Astúrias, na Espanha setentrional. Falla recolheu a melodia e o texto da ária popular Asturiana, mas o acompanhamento do compositor remodela a peça”. ${ }^{20}$

Similar ao que acontece com o Polo, a transcrição de Colón para a Asturiana é idêntica à de Maréchal. Nas duas versões, a primeira apresentação do tema é colocada uma oitava abaixo. Já em sua repetição, no entanto, o tema é apresentado em seu registro original (comp. 21-31). Certamente, neste caso, a exploração de registros busca adicionar certa variedade de timbre.

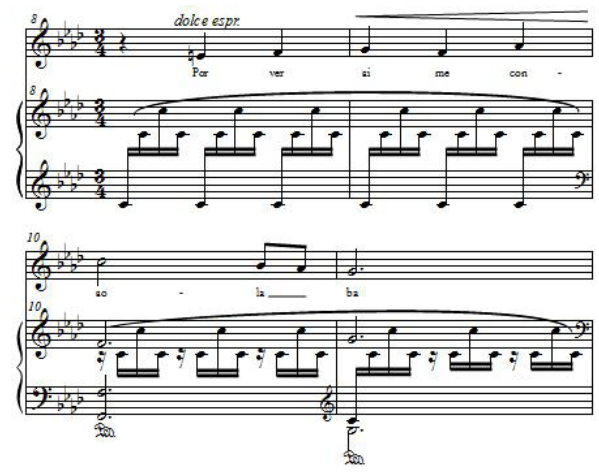

Exemplo 6a - Siete Canciones Populares Españolas - Asturiana (comp.8-11).

Fonte: Versão original para canto e piano de Manuel de Falla (1922). 


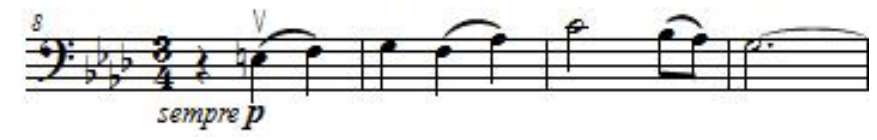

Exemplo 6b - Suite Populaire Espagnole - Asturiana (comp.8-11).

Fonte: Manuel de Falla (transcrição de Maurice Maréchal) (1925).

Salienta-se, mais uma vez, que Colón e Maréchal posicionam a canção em lugares distintos: o primeiro a coloca como a terceira canção, seguindo a ordem de Manuel de Falla. Por sua vez, Maréchal a posiciona como a quinta canção, antecedendo o movimento conclusivo de seu ciclo.

\subsection{Jota}

A canção escolhida por Maréchal para concluir o ciclo é a Jota. Esta deriva de uma dança do norte da Espanha e, como expõe Nevado ([entre 2001 e 2015, tradução nossa]), "os estudiosos de Falla não estão de acordo sobre a origem do tema. Para muitos, o tema original da brilhante e luminosa jota procede quase que exclusivamente da imaginação criadora de Falla, ainda que se observe o estilo e forma do protótipo genuinamente aragonês". ${ }^{21}$ Ademais, Park (2013, p. 18, tradução nossa) argumenta que "a jota está entre as mais celebradas formas de dança espanhola e este é o mais famoso dentre os sete movimentos das Siete Canciones Populares Españolas". ${ }^{22}$

Esta canção é a mais longa em termos de número de compassos em toda a suíte, com uma introdução do piano solo por 32 compassos, sendo que a linha da voz se inicia apenas no compasso de número 33, de acordo com a versão original de Falla. Observa-se, todavia, que Colón adota as mesmas estratégias que Maréchal, notadamente no que diz respeito à inserção de alguns elementos da textura pianística na linha do violoncelo. Desta forma, o violoncelo realiza não somente a linha da voz, mas também algumas linhas oriundas do piano.

Logo de início, Maréchal constrói uma linha em pizzicatos no violoncelo- ora com notas da mão esquerda do piano (comp. 1-8) ora com acordes (comp. 9-16). Adicionalmente, nos compassos seguintes (comp. 17-24), a mão direita do piano é transcrita para o violoncelo, que a realiza com o arco. Por fim, os pizzicatos em acordes retornam entre os comp. 25-32, antecedendo o que seria, originalmente, a entrada da voz no comp. 33. Colón aplica esse mesmo gesto na linha do violoncelo e, nos compassos 25-32, adiciona a indicação "quasi chitarra" - que não aparece na versão de Maréchal - com a intenção de enfatizar as sonoridades violonísticas emuladas pelo violoncelo. No entanto, neste caso, Colón omite a repetição de notas presentes na edição de Maréchal, conforme Exemplo 10 c.

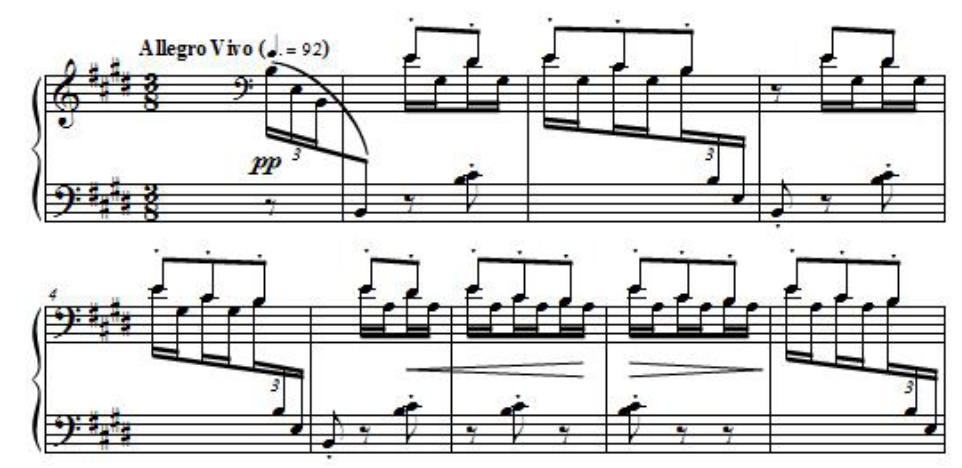

Exemplo 7a - Siete Canciones Populares Españolas - Jota (comp. 1-8).

Fonte: Versão original para canto e piano de Manuel de Falla (1922). 


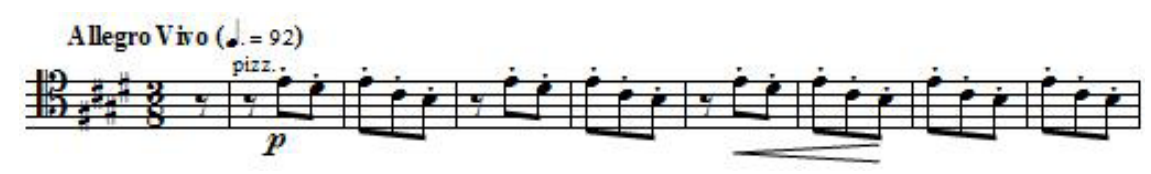

Exemplo 7b - Suite Populaire Espagnole - Jota (comp. 1-8)

Fonte: Manuel de Falla (1925) (transcrição de Maurice Maréchal).
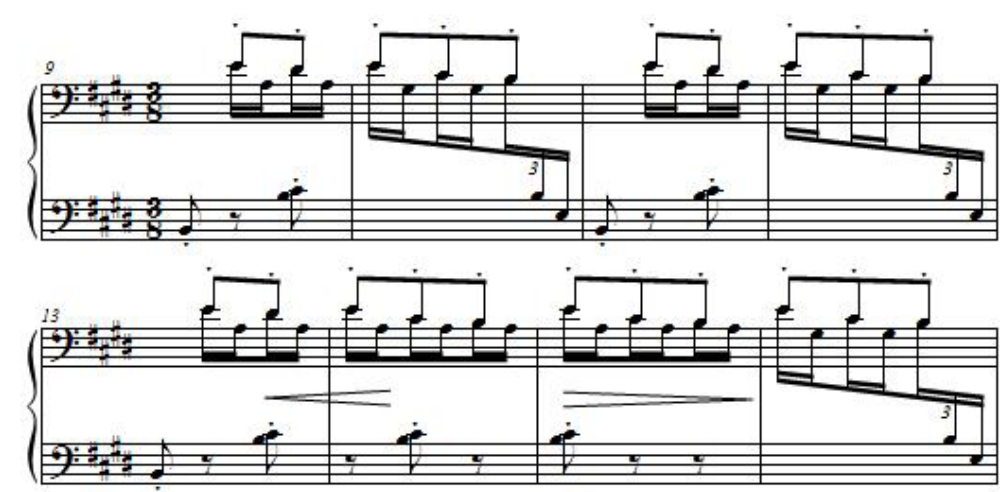

Exemplo 8a - Siete Canciones Populares Españolas - Jota (comp. 9-16)

Fonte: Versão original para canto e piano de Manuel de Falla (1922).

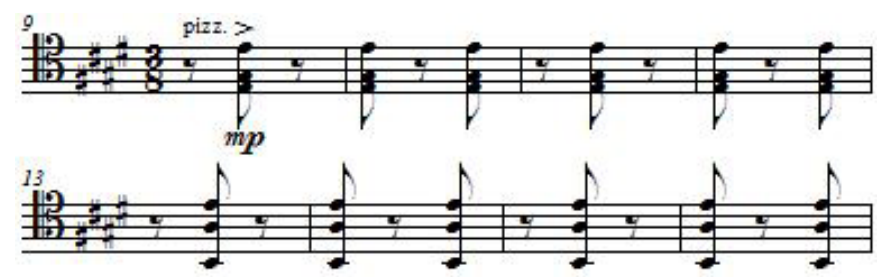

Exemplo 8b - Suite Populaire Espagnole - Jota (comp. 9-16)

Fonte: Manuel de Falla (1925) (transcrição de Maurice Maréchal)

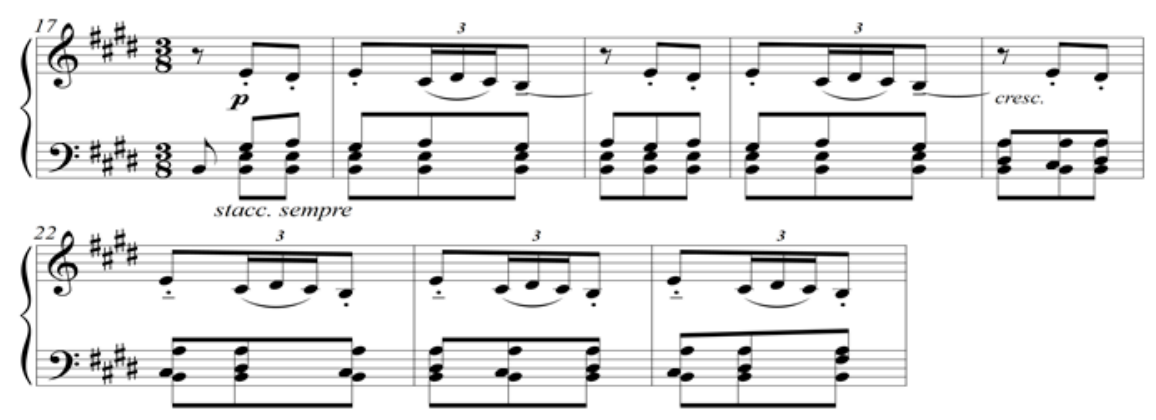

Exemplo 9a- Siete Canciones Populares Españolas - Jota (comp. 17-24)

Fonte: Versão original para canto e piano de Manuel de Falla (1922).

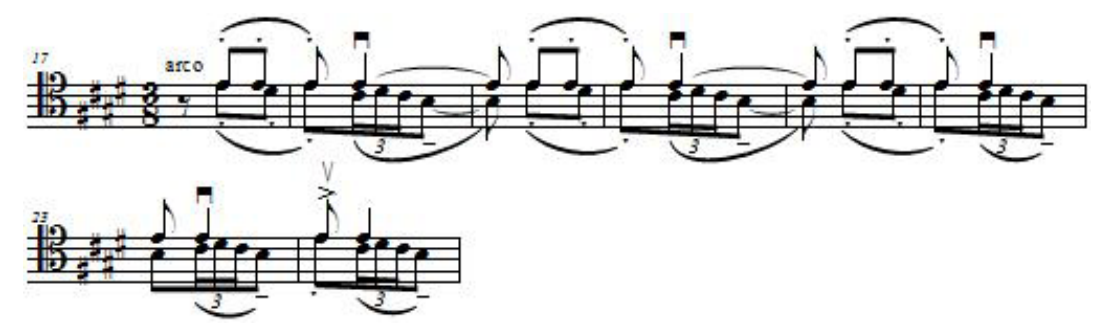

Exemplo 9b- Suite Populaire Espagnole- Jota (comp. 17-24)

Fonte: Manuel de Falla (1925) (transcrição de Maurice Maréchal). 

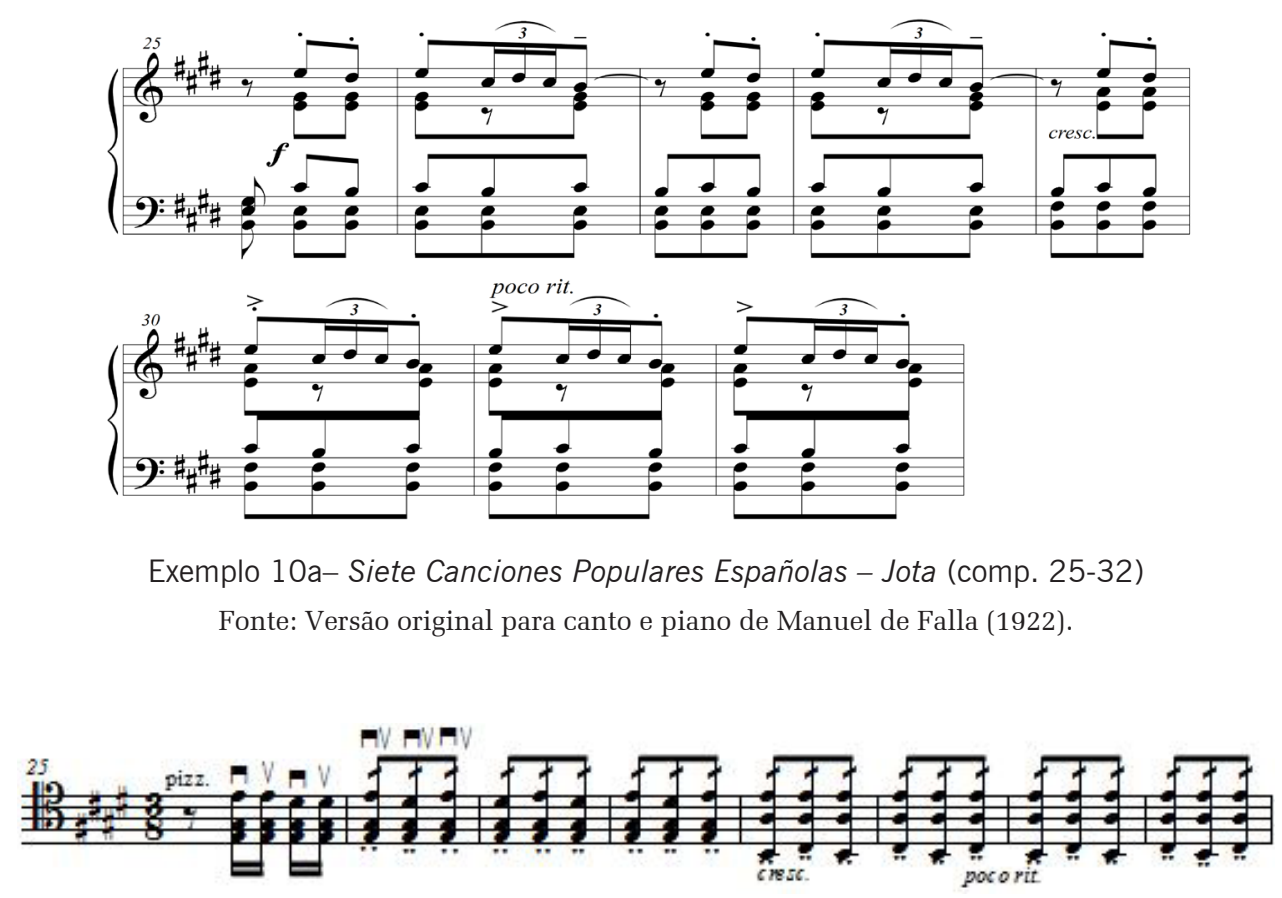

Exemplo 10b- Suite Populaire Espagnole- Jota (comp. 25-32).

Fonte: Manuel de Falla (1925) (transcrição de Maurice Maréchal).

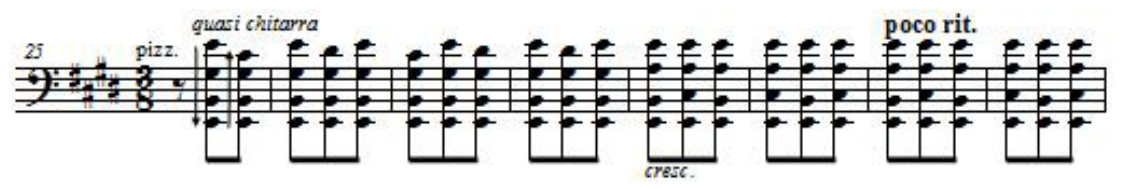

Exemplo 10c- Siete Canciones Populares Españolas - Jota (comp. 25-32)

Fonte: Manuel de Falla (2002) (transcrição de Emilio Colón)

Conforme prática adotada anteriormente, o trecho que abrange os compassos 61 a 90 seria, originalmente, para piano solo. Verifica-se que a solução aplicada por Maréchal é, da mesma forma, seguida por Colón. Sendo assim, temos seis compassos de piano solo (comp. 61-66) seguidos por uma linha no violoncelo, em semicolcheias, que funciona como uma reelaboração da versão original. A partir deste ponto, a textura se torna muito mais densa, tanto pela adição da linha do violoncelo, quanto pelo enriquecimento da textura da parte do piano (comp. 67-82). Por outro lado, a transcrição da parte, originalmente realizada pela voz, a partir do comp. 91, é feita de maneira semelhante pelos dois arranjadores.

\section{Conclusão}

Maurice Maréchal, violoncelista que construiu sua a carreira apresentando obras consagradas da literatura do violoncelo, foi também responsável por realizar vários arranjos e transcrições, consolidando algumas destas versões no repertório do instrumento, como é o caso de seu arranjo da Suite Populaire Espagnole para violoncelo e piano.

Este estudo comparativo deixa claro que o original de Manuel de Falla, sob o título de Siete Canciones Populares Españolas para canto e piano, foi revisado e arranjado pelo violinista Paul Kochański, juntamente com o compositor, e foi transformada em uma suíte instrumental sob o novo título de Suite Populaire Espagnole.

Imagina-se que, devido ao forte caráter vocal e declamatório da Seguidilla Murcia- 
na, que não se adequa tão bem às características do violino, este movimento foi omitido na versão de Falla-Kochański. Salienta-se que foi esta versão que serviu como ponto de partida para as decisões musicais de Maréchal. Isto demonstra, portanto, como a escolha da instrumentação pode vir a refletir no escopo estrutural de uma obra. Neste caso, a escolha do violino e piano ensejou a omissão de um movimento, o completo reordenamento de sua sequência, culminando com a adequação de um novo título à obra.

O estudo salienta, por outro lado, que Emilio Colón optou por realizar um arranjo a partir da versão original das Siete Canciones Populares Españolas, para canto e piano. Desta forma, seu arranjo nos oferece a íntegra da série de canções, incluindo a Seguidilla Murciana, com todas as suas características vocais e declamatórias, que tão bem se adequam ao idiomatismo do violoncelo. A partir desta nova roupagem da obra, com edição de 2002, Colón demonstra que se distancia em diversos aspectos da versão de seu predecessor, mantendo a estrutura e sequência de sete movimentos da versão original para voz e piano, além de combiná-la com algumas das características do arranjo de Maréchal. Ademais, Colón adiciona, na parte do violoncelo, elementos muitas vezes extraídos da própria parte de piano, seja para acrescentar algum componente virtuosístico, para acentuar um determinado caráter da canção, a título de adorno, ou até mesmo em busca de um timbre específico.

Destarte, nós violoncelistas somos agraciados com duas versões de uma mesma obra de Manuel de Falla, sendo a primeira versão baseada na elaboração instrumental para violino e piano, e a segunda realizada a partir da primeira versão desta obra, originalmente para canto e piano. Cada qual com características distintas, conforme aqui destacadas, ambas se constituem em importante adição ao repertório do instrumento. Ademais, verificamos que as decisões editoriais refletem a personalidade artística de cada um dos arranjadores, espelhando, ao mesmo tempo, referências artístico-estéticas de suas respectivas épocas. Aspecto esse que descerra novas perspectivas àqueles que se interessam pelo estudo das características estilísticas das distintas escolas de performance do violoncelo, através do resgate do processo estético-criativo do início do séc. XX, como também da evolução técnica do instrumento ao longo deste século.

\section{Notas}

${ }^{1}$ Emilio Colón, violoncelista nascido em Porto Rico, é professor da Jacobs School of Music da Indiana University EUA, e é também reconhecido concertista, pedagogo, compositor e editor. Por se tratar de um violoncelista em plena atuação, cujo impacto do trabalho é amplamente reverberado, decidiu-se por não incluir dados biográficos deste arranjador no presente trabalho.

2 "Entre le 3 mai 1914 et le 8 février 1919 neuf calepins se sont succédé dans une poche de l'uniform, assez minces et de format réduít pour ne pas gêner les mouvements". (LAMBERT, 2003, p. 19).

${ }^{3}$ Sobre a presença de violoncelistas no fronte da $1^{\mathrm{o}}$ Guerra Mundial e os instrumentos construídos a partir de caixa de munição, ver também: Isserlis e Shih (2018).

${ }^{4}$ Curiosamente, observa-se que "Poilu" é o nome dado aos soldados franceses da $1^{\mathrm{a}}$ Guerra Mundial.

${ }^{5}$ Pedrell foi também professor de Albéniz e Granados, outros dois importantes representantes do nacionalismo musical espanhol.

6 “Kochański’s transcriptions represent a personal connection with the original composer. For example, in 1907, Kochański had not only performed in Bilbao with Manuel de Falla as pianist but also financially assisted the Spaniard to go to Paris, thus furthering the latter's professional growth. The transcription of de Falla's Siete canciones populares espanolas for voice and piano (1914-15), for which the violin and piano parts were revised by Kochański and the composer, respectively, also lists the violinist as a dedicatee. Retitled Suite populaire espagnole, the work is among the most popular of Kochański many transcriptions". (GREIVE, 1998).

7 "The melody of this song is taken from the popular Andalusian air 'El paño', but Falla slightly changes the melody”. (PARK, 2013, p. 7).

8 "In terms of cello technique, harmonics and various pizzicato figures are supplied in 'El paño moruno"”. (PARK, 2013, p. 9). 
9 "As the cello harmonics double the same notes two octaves higher than the accentuated second beat of the piano, the accompaniment distinctly obtains more energy from the cello part”. (PARK, 2013, p. 9).

10 “The first, El Paño moruno (The Moorish Cloth), gives a none-too-veiled warning to young girls to avoid the 'stain' of an illicit love affair while the second, the Seguidilla murciana, is an intense argument of insistent taunts and bitter bant”. (GISLASON, 2014). Disponível em: <http://vanrecital.com/tag/de-falla/>. Acesso em: 16 de fevereiro de 2016.

11 "The nana is an Andalusian cradle song that Falla first heard from his mother during his childhood". (PARK, 2013, p. 22)

12 “'Nana' is in binary form and is structured as follows: A (mm. 1-19) - A' (mm. 20-37). Unlike the original vocal version of 'Nana' by Falla, which has only one verse, the cello arrangement has a repeated section played an octave higher. The repetition is basically the same as the first verse”. (PARK, 2013, p. 22)

13 "Es un agridulce canto de amor (a pesar de la indicación de Falla para el canto: 'com grazia') oriundo de Granada, para cuyo acompañamiento Falla construye un obstinado ritmo que culminará fundiéndose con la voz o el cello en una brevíssima coda”. (NEVADO [entre 2001 e 2015]). Disponível em: <http://ibsclassical.com/en/recordings/ fallacassado/libretofalla?start=4:>. Acesso em: 31 de julho de 2014.

14 "En la versión de cello y piano, Maréchal realiza algunas variantes para el lucimiento solista, con escribir el tema en el compás 31 -precedido de un gran crescendo- en dobles cuerdas y volumen ff, cuando la partitura original se mueve en el ámbito del pp. Asimismo reserva al cello una nota tenida que asciende a una octava (con glissando opcional) en los tres últimos compases, inexistente en la versión de voz”. (NEVADO [entre 2001 e 2015]). Disponível em: <http://ibsclassical.com/en/recordings/fallacassado/libretofalla?start=4:>. Acesso em: 31 de julho de 2014

15 “Es la más brillante y desagarrada del ciclo, por lo que Falla opta por dejarla para el final. El autor mira de nuevo a Andalucía y al Cante Jondo”. (NEVADO, [entre 2001 e 2015]). Disponível em <http://ibsclassical.com/en/recordings/fallacassado/libretofalla?start=4:>. Acesso em: 08 de agosto de 2014.

${ }_{16}$ "Se da el nombre de cante jondo a un grupo de canciones andaluzas, cuyo tipo genuino y perfectoes la siguiriya gitana, de las que derivan otras canciones aún conservadas por el pueblo, como lospolos, martinetes, carceleras y soleares”. (LORCA, 1922) Disponível em: < http://gnawledge.com/pdf/granada/LorcaCanteJondo.pdf>. Acesso em: 16 fevereiro de 2016.

17 "The Siguiriya (Siguiriyas plural) was first called the Seguida. Later the diminutive suffix -illa was added making the Seguidilla. Through a phonetic deformation the Seguidilla became known as the Siguiriyas”. (ZUSSMAN, 1995). <http:/gnawledge.com/pdf/granada/LorcaCanteJondo.pdf>. Acesso em: 16 fevereiro de 2016.

18 "El cante jondo se acerca al trino del pájaro, al canto del gallo y a las músicas naturales delbosque y la fuente". (LORCA, 1922). <http:/gnawledge.com/pdf/granada/LorcaCanteJondo.pdf>. Acesso em: 16 fevereiro de 2016.

19 "The musical expressions of rapidly and roughly repeated notes, accents, and staccati convey the grief and bitter feeling of the speaker". (PARK, 2013, p. 31).

20 “The lamenting song 'Asturiana' is from Asturias in northern Spain. Falla took the melody and text from this popular Asturian air, but his own accompaniment reshapes the piece”. (PARK, 2013, p. 15).

21 "Los estudiosos de Falla no se ponen de acuerdo en el origen del tema. Para muchos el tema original de la brillante y luminosa jota, procede casi en exclusividad de la imaginación creadora de Falla, aún cuando mire en estilo y forma al prototipo genuinamente aragonés". (NEVADO [entre 2001 e 2015]). <http://ibsclassical.com/en/recordings/fallacassado/libretofalla?start=4:>. Acesso em: 13 de agosto de 2014.

22 "The jota is among the most renowned of Spanish dance forms, and this movement is the most famous among the seven of Siete canciones populares Españolas”. (PARK, 2013, p. 18).

\section{Referências}

DE FALLA, Manuel. Siete Canciones Populares Españolas. Adaptação francesa de M. Paul Milliet. Paris: Max Eschig, 1922. 32 p.

Siete Canciones Populares Españolas. Transcrita e editada por Emilio Colón. Boca Raton: Ludwig Masters, 2002.

.Siete Canciones Populares Españolas. Transcrita para o violoncelo por Maurice Maréchal. Paris: Max Eschig, 1925.

GINSBURG, Lev. History of the violoncello. Nova Jersey: Paganiniana Publications, 1983. 384 p.

GISLASON. Donald. Notas de programa: Yo-Yo Ma \& Kathryn Stott. 2014. Disponível em: 
<http://vanrecital.com/tag/de-falla/> Acesso em 18 fev. 2016.

GREIVE, Tyrone. Kochański’s collaborative work as reflected in his manuscript collection. Polish Music Journal, v. 1, n. 1, summer 1998. ISSN 1521 - 6039. Disponível em:

<http://pmc.usc.edu/PMJ/issue/1.1.98/kochanski_part1.html>. Acesso em 8 fev. 2018.

GROUT, Donald J.; PALISCA, Claude V. A history of Western music. 4. ed. Nova York: W.W. Norton, 1988. $559 \mathrm{p}$.

ISSERLIS, Steven; SHIH, Connie. The cello in wartime: Debussy, Bridge, Fauré, Webern, and pieces played on a trench cello. CD [BIS2312]. Bis Records, 2018. (ca. 65 min)

LAMBERT, Alain. Maurice Maréchal: la voix du violoncelle. Genève, Suisse: Edition Papillon;7º note, 2003. $133 \mathrm{p}$.

LORCA, Garcia. [1922] Importancia historica y artistica del primitive canto andaluz llamado "Cante Jondo". 2012. Disponível em: < http://gnawledge.com/pdf/granada/LorcaCanteJondo.pdf>. Acesso em: 21 agosto 2014.

MAURICE MARÉCHAL: a musician in the Great War. 2013. Disponível em <http://centenaire. org/en/autour-de-la-grande-guerre/maurice-marechal-musician-great-war> Acesso em: 10 maio 2014.

NEVADO, Juan Antonio Higuero. Falla \& Cassadó: Obras para violoncello y piano. [entre 2002 e 2015]. Disponível em <http://ibsclassical.com/en/recordings/fallacassado/libretofalla?start=4> Acesso em: 31 de maio 2015.

PARK, Jihyun. A Study of Siete canciones populares Españolas by Manuel de Falla. 2013. 42 f. Tese (Doutorado). School of Music of the University of Kansas, 2013. Kansas: KU, 2013.

PEREIRA, Flavia Vieira. As práticas de reelaboração musical. 2011. 308 f. Tese (Doutorado). Programa de Pós-Graduação em Artes da Universidade de São Paulo, 2011. São Paulo: USP, 2011.

RANDEL, Don Michael. Arrangement. In: RANDEL, Don Michael (Ed.). The new Harvard dictionary of music. Cambridge: The Belknap Press of Harvard University Press, 1986. 1008 p.

ZUSSMAN, Benett Thomas. The Siguiriyas song form in flamenco guitar: a historical and comparative study. 1995. 79 f. Dissertação (Mestrado). Department of Art and Art History of San Jose State University. Califórnia: SJSU, 1995.

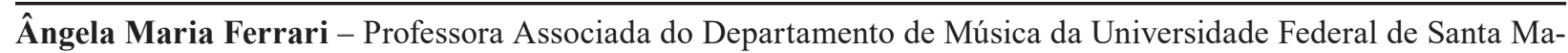
ria (UFSM) é responsável pela implantação do bacharelado em violoncelo na instituição. Estudou na University of Notre Dame obtendo o título de mestre em Artes Musicais - Violoncelo. Cursou o doutorado em Artes Musicais na University of Miami, ganhando o prêmio "Excellence in Academy" ao final do doutorado. Em 2003 com a bolsa Virtuose estudou na Academia Nacional de Sofia - Bulgária, com o Professor Anatole Krastev.
}

Felipe Avellar de Aquino - Violoncelista paraibano, possui mestrado em violoncelo pela Louisiana State University e doutorado pela Eastman School of Music (University of Rochester). Tem se presentado no Brasil, Argentina, Itália, EUA e Canadá. Atualmente é professor titular do Departamento de Música da Universidade Federal da Paraíba (UFPB), onde leciona Violoncelo e Música de Câmera. Nessa Universidade, coordenou o processo de implantação do Programa de Pós-Graduação em Música. Tem artigos publicados pelas revistas The Strad (Inglaterra), Per Musi e Opus. 